\title{
THE INTRA ORAL WOUND HEALING EFFECT OF METFORMIN IN NON DIABETIC ALBINO RATS AN EXPERIMENTAL STUDY
}

\author{
DR. SARITHA. M. $\mathrm{K}^{1} \&$ DR. CHANDRASHEKAR. $\mathrm{K}^{2}$ \\ ${ }^{1}$ Assistant Professor, Department of Dentistry, Chettinad Hospital and Research Institute, Kelambakkam, Tamil Nadu, India \\ ${ }^{2}$ Associate Professor, Department of Pharmacology, Chettinad Hospital and Research Institute, Kelambakkam, Tamil Nadu, India
}

\begin{abstract}
Purpose: Wound healing is a crucial survival mechanism in human beings. It follows a sequence of complex biological processes and sequences. All oral tissues heal with a similar process with minimal scar formation. Wound healing occurs in the oral cavity in the presence of warm oral fluid containing millions of microorganisms. It is possible to manipulate wound healing favourably by various drugs and factors. Insulin promotes wound healing, by increasing cellular proliferation, angiogenesis, mineralization of tissue and by decreasing apoptosis. Its pro healing property in non diabetic individuals is compromised by its hypoglycaemic side effects. Metformin, a biguanide, is currently the drug of choice for type 2 diabetes. Few studies have studied the effect of metformin to influence wound healing. Recently, Metformin received increasing attention because of its anti-inflammatory properties on non diabetic wounds. Therefore the effect of metformin on intra oral wound healing in non diabetic albino rats was planned.
\end{abstract}

Experimental Design: Metformin was administered to senile rats for 16days. A section of the gingiva was removed to denude the palatal bone. Wound size, biological parameters, blood glucose were assessed and histologic sections were analyzed to determine the wound healing status.

Results: The wound closure was observed on $4^{\text {th }}, 8^{\text {th }}, 12^{\text {th }}$ and $16^{\text {th }}$ day. When compared to control, metformin treated groups showed enhanced wound closure.There was a significant increase in hydroxy proline concentration measured on days $8^{\text {th }}$ and $16^{\text {th }}$ day in metformin groups compared to control group. No significant differences in blood glucose levels $(\mathrm{mg} / \mathrm{dl})$ were observed after $8^{\text {th }}$ and $16^{\text {th }}$ days of drug treatment.

Conclusions: Met for min showed significant intraoral healing compared to control groups. Immuno histology staining showed rich vascularity and angiogenesis in the examined soft tissue

KEYWORDS: Metformin, Non Diabetic Rats, Intraoral Wound, Wound Healing

\section{INTRODUCTION}

A wound is a common clinical entity encountered in a day to day practice. Wound healing follows a sequence of complex biological processes and sequences.. Wound healing is a specific biological and highly dynamic process, involving complex integrated, anatomical, physiological and biochemical changes, progressing in an orderly manner at an optimal rate, which may differ from species to species. Wound healing occurs in the oral cavity in the presence of warm oral fluid containing millions of microorganisms. Oral cavity wound heals without scar formation. The restoration of this damaged tissue constitutes wound healing and it includes both tissue repair and regeneration. In humans, the healing time is much faster in intestinal wounds and relatively slow in intra oral and skin wounds. 
With the advancement and better understanding of physiology and pathology of wound healing, it is possible to manipulate wound healing favourably by various drugs and factors. Literature survey points out that several drugs and chemicals have been studied to assess their wound healing property, many of them favour and others retarded wound healing. Wound healing is also affected in the presence of other pathologies like infection, foreign body, malnutrition, diabetes and many more.

Insulin has been found to enhance wound healing, by increasing cellular proliferation, angiogenesis, mineralization of tissue, and by decreasing apoptosis in wounds. Its pro healing property in non diabetic individuals is compromised by its hypoglycaemic side effects. Metformin, a biguanide, is currently the drug of choice for type 2 diabetes. Despite metformin was one of oldest prescribed hypoglycemic agents for patients with type 2 diabetes, few studies have investigated the effects of metformin on wound healing. Recently, Metformin was received increasing attention because of its anti-inflammatory propertie. However, there is sparse information about the pro-healing effect of metformin on non diabetic wounds in oral cavity. So the effect of metformin on intraoral wound healing in non diabetic albino rats was planned.

\section{AIMS AND OBJECTIVES}

To evaluate wound healing property of metromin on intra oral wounds in non diabetic Wistar albino rats.

\section{MATERIALS \& METHODS}

The experimental design and protocol were reviewed and approved by institutional ethics committee. Healthy Wistar albino rats of both sex, weighing around 200- $250 \mathrm{gm}$ of 8 to 10 months age were selected for the study. They were divided into 2 groups of 8 each and among them 3 rats were to be sacrificed on the eighth day and 3 rats on the sixteenth day after starting the experiment. The rats were housed in a clean poly propylenecage kept in an experimental condition with 12 hours alternate natural light and night cycles in temperature maintained $23-25^{\circ} \mathrm{C} \&$ with relative humidity of 50 $60 \% \&$ allowed to a free access of standard pellet food \& water.

The metformin was obtained from pharmaceutical companies in pure powder form of IP grade. Clinical doses of these drugs were equivalently converted in to rat doses using the converting table as described by Paget \& Barns ${ }^{17}$ and they were administered to the rats daily per orally. Drugs were suspended in $1 \%$ gum acacia so as to obtain the required dose in $1 \mathrm{ml}$ and administered every $24 \mathrm{hrs}$ (10:00am) using tuberculin syringe until the complete epithelisation of excised wound occurs. Group 1 served as control and received $1 \%$ gum acacia and group 2receiveddrug metformin.

Table 1

\begin{tabular}{|l|l|}
\hline Group & Treatment \\
\hline Group 1 & $\begin{array}{l}\text { Control } \\
\text { Gum acacia oral }\end{array}$ \\
\hline Group 2 & Metformin $180 \mathrm{mg} / \mathrm{kg}$ \\
\hline
\end{tabular}

\section{Methods}

- Excision Wound: The rats were starved overnight, but with free access to. Palatal wounds were created to assess the healing of the denuded palatal bone. Rats were anesthetized and the palatal mucosa in first molar region was excised to denude the alveolar process of the palatal bone. The size of the excised palatal mucosa was approximately measuring $2 \times 2 \mathrm{~mm}$, with a depth of 2-3 mm. The denuded palatal bone was utilised to study 
spontaneous wound healing. Measures were taken to control bleeding and infection. Wound closure rate was assessed spontaneously by observing on wounding day (0) followed by $4^{\text {th }}, 12^{\text {th }}, 16^{\text {th }}$ day and subsequently on every alternate day/daily till complete closure has occurred. Excision wound healing was assessed by time of epithelialisation.

- Histopathological assessment of exicised wound granulation tissue: Biopsy of intraoral wound was performed on $16^{\text {th }}$ day of experiment and rats were sacarified with excess dose of ether anaesthesia and biopsied tissue was subjected for histopathological examination under microscope for the assessment of fibroblast population, infiltrating cells, collagen content and angiogenesis.

- Biochemical analysis: Three $\mathrm{ml}$ blood was collected from sacrificed animal of each group on $8^{\text {th }}$ and $16^{\text {th }}$ day of experiment and plasma was separated by centrifugation and stored at $-90^{\circ} \mathrm{C}$ and subjected for estimation of hydroxyproline using Elisa kit.

- Blood glucose estimation using glucometer.

\section{Statistical Analysis}

All the results were expressed as mean \pm SEM \& significant difference between the means was analyzed using One-way ANOVA followed by post hoc (Tukey's) test. Values at $\mathrm{p}<0.05$ were considered statistically significant.

\section{RESULTS}

In the present study, metformin have been investigated for their influence on intraoral wound healing in normal albino wistar rats and results were as follows,

- The wound closure was observed spontaneously on $4^{\text {th }}, 12^{\text {th }}$ and $16^{\text {th }}$ day: Metformin treated groups showed significantly enhanced wound closure compared to control group.

- Time for complete epithelisation: Total time for complete epithelialization decreased in the metformin treated groups. Metformin group showed complete epithelisation in $17.33 \pm 0.2$ days compared to control group of $20 \pm 0.2$ days (Table 2 ).

- There was significant increase $(\mathrm{p}<0.05)$ in hydroxyproline concentration measured on days $8^{\text {th }}$ and $16^{\text {th }}$ day in metformin treated groups compared to control group. (Table 3)

- No significant differences in blood glucose levels $(\mathrm{mg} / \mathrm{dl})$ were observed after 8th or 16thdays of drug treatment. (Table 4)

- Histopathology examination of healed wound area: Histology was evaluated on 8thand 16thday after wounding. Wound enclosure was found to be smaller in metformin groups. There was abundant granulation tissue with increased amount of collagen and new blood vessels in metformin treated groups as compared to that of control group. 
Table 2: Time for Complete Epithelization in Wound Area

\begin{tabular}{|l|c|c|}
\hline & Control & Metformin \\
\hline $\begin{array}{l}\text { Time for complete } \\
\text { epithelialization } \\
\text { (days) }\end{array}$ & $20 \pm 0.2$ & $17.330 .2108^{*}$ \\
\hline
\end{tabular}

Mean $\pm S E M *$ denotes Significant $(\mathrm{p}<0.05)$ decrease in time (days) for epithelialization in metformin compared to control

Table 3: Serum Hydroxyproline on 8th and 16th Day

\begin{tabular}{|c|c|c|c|}
\hline Day & & Control & Metformin \\
\hline 8 & $\begin{array}{c}\mathrm{HYP} \\
\mathrm{ng} / \mathrm{ml}\end{array}$ & $573.44 \pm 0.7$ & $661.57 \pm 1.57^{*}$ \\
\hline 16 & $\begin{array}{c}\mathrm{HYP} \\
\mathrm{ng} / \mathrm{ml}\end{array}$ & $698.75 \pm 0.7$ & $780.41 \pm 1.57 *$ \\
\hline
\end{tabular}

Mean \pm SEM* denotes Significant $(\mathrm{p}<0.05)$ Increase in hydroxyproline $(\mathrm{HYP})$ content in the metformin group compared to control No significant variations in blood glucose levels in drug treated and control group

Table 4: Blood Glucose Level (Mg/Dl) on Day 0,8 and 16

\begin{tabular}{|c|c|c|c|}
\hline Days & $\mathbf{0}$ & $\mathbf{8}$ & $\mathbf{1 6}$ \\
\hline Control & 67 & 70 & 86 \\
\hline Metformin & 68 & 74 & 82 \\
\hline
\end{tabular}

No significant variations in blood glucose levels in drug treated and control groups

\section{DISCUSSIONS}

The aim of the present study was to investigate the effect of metforminon non diabetic wound healing in oral cavity. The wound closure was significantly higher in metformin groups with complete wound closure by epithelialisation than the control group. This was the result of good granulation tissue formed at wound site, as evidenced by biopsy of wound tissue on $12^{\text {th }}$ day, containing abundant granulation tissue with increased amount of collagen. This indirectly points out that metformin appeared to act by promoting angiogenesis and halting an ongoing active inflammatory process in the wound. Hydroxyproline is a non essential amino acid synthesized in liver, required for collagen synthesis which is the integral part of wound healing \& repair. ${ }^{19}$ Thusmetforminpromote wound healing by their property of angiogenesis and collagenation with some anti-inflammatory action.

The results of present study is in accordance with the earlier study where hyperglycemic type 2 diabetic rats showed wound healing around oral implants after metformin administration. ${ }^{20}$ It has been hypothesized that high levels of glucose in the blood leads to the formation of irreversible advanced AGEs that can bind to RAGE and can accumulate on fibroblasts. When this occurs, there can be more destruction of connective tissue and bone because of a decrease in collagen synthesis and increase in inflammatory mediators. ${ }^{21}$. The prohealing activity of metformin in diabetic individuals may be due to its antihyperglycemic activity as diabetic patients are more prone for infection, ${ }^{22}$ apart from this metformin is also known to increase angiogenesis through activation of AMPK in hepatocytes. ${ }^{23}$

However, the present study would have included more wound models and direct evidence of biochemical parameters from wound biopsy rather than from serum. Prohealing activity of metformin could be utilized to treat non healing wounds in non diabetic patients in oral cavity. To utilize the prohealing activity of these drugs further clinical trials to evaluate intraoral wound healing are in need. 


\section{CONCLUSIONS}

Metformin, anti diabetic drug has pro-healing effect with enhanced intraoral wound healing compared to control group in non diabetic rats. Thus, they become the drug of choice in the non diabetic wound management and promoting wound healing. They could be prescribed even in non diabetics with wounds or peri surgically, exploiting their pro healing activity. However, further clinical studies area required for their new role.

\section{REFERENCES}

1. Howes EL, Harrey SG, Hewitt C. Rate of fibroplasias and differentiation in the healing of cutaneous wounds in different species of animals. Surgery 1939;38:934.

2. Chandrashekar K, Vinayaka M, Rukmani. Effect of 0.2\% GTN ointment on wound healing in sterptozotocin induced diabetes rats an experimental study. Asian J Med Cli Sci. 2012;1(2):86-88.

3. Rosenthal S, Lerner B, Dibiase F, Enquist IF. Relation of strength to composition in diabetic wounds. Surg Gynaecol Obstet.1962; 115:437-442.

4. Shah Z, Kampfrath T, Deiuliis JA. Long-term dipeptidyl-peptidase 4 inhibition reduces atherosclerosis and inflammation via effects on monocyte recruitment and chemotaxis. Circulation. 2011; 124:2338-49.

5. Vittone F, Liberman A, Vasic D. Sitagliptin reduces plaque macrophage content and stabilises arterio-sclerotic lesions in ApoE (-/-) mice. Diabetologia 2012; 55: 2267-75.

6. Terasaki M, Nagashima M, Watanabe T. Effects of PKF275-055, a dipeptidyl peptidase-4 inhibitor, on the development of atherosclerotic lesions in apolipoprotein E-null mice. Metabolism 2012; 61:974-78.

7. Tsukimi Y, Nozue C, Okabe S. Effects of leminoprazole, Omeprazole and Sucralfate on Indomethacin induced delayed healing of kissing gastric ulcers is rats. J Gastroenterol Hepatol. 1996;11(4):335-40.

8. Drucker DJ, Nauck MA. The incretin system: Glucagon-like peptide-1 receptor agonists and dipeptidyl peptidase-4 inhibitors in type 2 diabetes. Lancet 2006; 368:1696-705.

9. Arakawa M, Mita T, Azuma K. Inhibition of monocyte adhesion to endothelial cells and attenuation of atherosclerotic lesion by a Glucagon like peptide-1 receptor agonist, Exenedin-4. Diabetes 2010;59:1030-37.

10. Patil PA, Swami T, Singh KR. Effect of Atorvastatin and Simvastatin on wound healing in albino rats. Pharmacology online. 2009; 2:963-74.

11. Chandrashekar $k$, Hogade A, Hiremath SV. Effect of anti leprotic agents on wound healing an Experimental study. Pharmacologyonline 2010; 3:270-75.

12. Cheng AY, Fantus IG. Oral antihyperglycemic therapy for type 2 diabetes mellitus. CMAJ. 2005; 172:213-226.

13. Jeyabalan. J \& B. Viollet \& P. Smitham \& S. A. Ellis \& G. Zaman, C. Bardin ET AL.. The anti-diabetic drug metformin does not affect bone mass in vivo or fracture healing. Osteoporos Int (2013) 24:2659-2670.

14. Arai M, Uchiba M, Komura H, Mizuochi Y, Harada $N$ and Okajima K. Metformin, an antidiabetic agent, suppresses the production of tumor necrosis factor and tissue factor by inhibiting early growth response factor-1 expression in human monocytes in vitro. J Pharmacol Exp Ther 2010; 334: 206-213.

15. Huang N. L, Chiang S. H, Hsueh C. H, Liang Y. J, Chen Y. J, Lai L. P. (2009) Metformin inhibits TNF- $\alpha$-induced IkB kinase phosphorylation, I $\mathrm{KB}-\alpha$ degradation and IL-6 production in endothelial cells through PI3K-dependent AMPK phosphorylation. Int. J. Cardiol. 134, 169-175. 
16. Panduranga Murthy, G, Chandrasekhar, K, \& Lokesh, S. (2015). Phyto-Chemical and Pharmacological Evaluation of EthnoMedicinal Plant Drugs (EMP) and Tribal Medicine Formulation (TMF) used by Tribal Practitioners for Wound Therapeutics in The Region of Biligirirangana Hills, Karnataka. International Journal of Research in Applied, Natural and Social Sciences, 3(7), 41-66.

17. Paget GE and Barns JM (1964). In Evaluation of Drug Activities: Pharmacometrics, eds. Laurence D R and Bacharach A L. vol 1, Academic press, New York and London.

18. Junro Yamashita, Kiyono Koi, Dong-Ye Yang, and Laurie K. McCauley. Effect of Zoledronate on Oral Wound Healing in Rats. Clin Cancer Res; 17(6) March 15, 2011.

19. McAnulty RJ. Methods for measuring hydroxyproline and estimating in vivo rates of collagen synthesis and degradation. Methods Mol Med. 2005; 117:189-207.

20. Guoyao Wu, \Fuller W. Bazer, Robert C. Burghardt, Gregory A. Johnson, Sung Woo Kim, Darrell A. Knabe, Peng Li, Xilong Li, Jason R. McKnight, M. Carey Satterfield, and Thomas E. Spencer. Proline and hydroxyproline metabolism: implications for animal and human nutrition. Amino Acids. 2011 Apr; 40(4): 1053-1063.

21. Lalla E, Lamster IB, Drury S, et al. Hyperglycemia, glycoxidation and receptor for advanced glycation end products: Potential mechanisms underlying diabetic complication, including diabetes-associated periodontitis. Periodontol 2000. 2000;23: 50-62.

22. Ridray S. Hyperinsulinemia and smooth muscle cell proliferation. Int J Obes Relat Metab Diord. 1995; 1:39-51.

23. Setyawan, $Y$, Sudjono Yuwono, H, \& Andean, R. (2017). Comparison on Infected Wound Healing Time, Using Coffee Powder and Honey in Wistar Rat. International Journal of General Medicine and Pharmacy (IJGMP), 6(6), 1-6.

24. Noriyuki Ouchi, Rei Shibata, Kenneth Walsh. AMP-Activated Protein Kinase Signaling Stimulates VEGF Expression and Angiogenesis in Skeletal Muscle. Circulation Research. 2005. 49:735-40. 